\title{
Plastik Enjeksiyon Üretim Bandında Kullanılan Kalıp ve Malzemeden Kaynaklı Meydana Gelen Üretim Hataları ve Giderme Yollarının Araştırılması
}

\author{
Yahya Taşgın*, Ali Gökkoru \\ Munzur Üniversitesi, Mühendislik Fakültesi, Makine Mühendisliği Bölümü, Tunceli, Türkiye \\ *yahyatasgin@munzur.edu.tr@, ali.gokkoruk@gmail.com $(\mathbb{D}$ \\ Makale gönderme tarihi: 17.04.2021, Makale kabul tarihi: 20.05.2021
}

\begin{abstract}
$\ddot{\mathbf{O} z}$
Plastik enjeksiyon kalıplama, endüstrinin her alanında yaygın olarak kullanılmaktadır. Bunun en önemli nedeni, enjeksiyon kalıpları ile istenilen şekil ve boyutlarda dikişsiz plastik ürünlerin kolayca üretilmesidir. Plastik ürünler kalıplama esnasında çok sayıda farklı parametreye maruz kalırlar. Bu yüzden, kalıplama parametrelerinin etkisini görerek doğru üretim yöntemleri oluşturmak amaçlanmaktadır. Bu çalışmada amaç; farklı özelliklerdeki malzemelerin, plastik enjeksiyon makineleri ile imalatı sırasında ortaya çıkabilecek imalat hatalarının daha önce tespit edilerek, hızlı ve doğru yöntemin belirlenmesi ve hataların minimuma indirgenmesidir. Yapılan çalışma sonucunda kalıp içerisinde kalan havanın üretim aşamasında neden olduğu sorunlar, sıvı ham maddenin akışı sırasında oluşabilecek türbülanslardan kaynaklı sorunlar, akış yollarının çakıştığı bölgelerde meydana gelen sorunlar, özellikle ince kesitli parçalarda ürün eksilme nedenleri, parçanın dişi kalıba yapışması, çapaklı ürün, yüzeyde çöküntü olması, çarpılma ve boşluklar gibi problemler tespit edilerek çözüm yolları üretilmiştir.
\end{abstract}

Anahtar Sözcükler: Kalıp, plastik enjeksiyon, üretim hataları, polipropilen

\section{The Investigation of Production Errors and Remedies Arising from the Mold and Material Used in the Plastic Injection Production Line}

\begin{abstract}
Plastic injection molding is widely used in all areas of the industry. The most important reason for this is that seamless plastic products in desired shapes and sizes can be easily produced with injection molds. Plastic products are exposed to many different parameters during molding. Therefore, it is aimed to create correct production methods by seeing the effect of molding parameters. The purpose of this study was to determine the fast and correct method and minimizing the errors by detecting the manufacturing defects that may occur during the production of materials with different properties with plastic injection machines beforehand. As a result of this study, the problems caused by the air remaining in the mold during the production phase, the problems caused by the turbulence that may occur during the flow of the liquid raw material, the problems that occur in the areas where the flow paths overlap, the reasons for product loss, especially in thin-section parts, the adhesion of the part to the female mold, the product with burr, as well as problems such as distortion and gaps were determined and solutions were provided.
\end{abstract}

Keywords: Mold, plastic injection, production defects, polypropylene

\section{GíRİș}

Plastik enjeksiyon kalıplarının tasarımı, maliyet hesabı ve imalatı seri üretim endüstrisinin en önemli alanlarından birini oluşturmaktadır. Plastik enjeksiyon kalıplarının tasarımı, hata yapma olasılığı fazla olduğu kadar pahalı ve yorucu bir çalışmayı gerektirmektedir. Tasarımın el ile yapıldığı yöntem, genelde uygun sonuçlar vermemekte veya tasarımcının bilgi ve tecrübesinin ağılık kazandığı sonuçlarla yetinilmesi gerekmektedir. Son yıllarda bilgisayar destekli sistemler, imalatın, özellikle tasarım aşamasında büyük zorluklarını azaltmak amacıyla kullanılmaktadır. Kalıp tasarımının ve imalatının uzun süreler alması, bu alanda birçok çalışma yapılmasına da neden olmuştur. Plastik enjeksiyon kalıplarının tasarımında, parça üzerinde bulunan unsurlar, kalıp maliyetini ve yapısını 
etkilemektedir. Plastik enjeksiyon kalıplama (PIM) polimer işlemedeki en önemli parça üretme prosesi olup, düşük maliyetlerle karmaşık parçaların üretimi için uygun bir yöntemdir. Her gün bir çok ürün PIM endüstrisinin teknolojisiyle üretilerek güven vermektedir. PIM, altı aşamadan oluşan bir süreçtir: kilitleme, doldurma, paketleme, soğutma, açma ve çıkarma. Tüm aşamalar birbirinden bağımsız değildir; uygunsuz sıkıştırma ayarı, başarısız bir doldurma aşamasına neden olabilir ve böylece genel sürecin performansını etkiler. Genellikle, bir PIM sürecinin performansı, parçaların nitelikleri gibi sonuçlara göre ölçülür, yani görünüm özellikleri, fonksiyonel özellikler ve verimlilik göstergeleridir (Kitayama ve ark.,2017; kuo ve ark.,2015; Li ve ark., 2018; Tian ve ark.,2017; Tsai ve ark.,2017; Zhao ve ark.,2015).

$\mathrm{Fu}$ ve ark. (1999), plastik parçaların üzerindeki unsurları tanımlayarak parçaların kalıplana bilirliğini belirlemeye yönelik bir çalışmalar yapmışlardır. Hui (1997), parçaların kalıplana bilirliğini belirlemek için geometrik bir yaklaşım sistemi geliştirmiştir. Plastik enjeksiyon kalıplarında, plastik malzemenin kalıp içerisinde akışının modellenmesi ve simülasyonu için de bir çok çalışma yapılmıştır (Nardin ve ark., 2002; Aisa ve ark., 2006).

Enjeksiyonla üretimde temel prensip, sicak plastiği kalıp içerisine basınçla gönderip eriyiğin kalıp boşluğunun şeklini alarak soğuyup sertleşmesini beklemektir. Kalıp sıcaklığı, baskı süresini belirleyeceğinden önemlidir. Sicak kalıpta ergimiş plastik, kolayca akmasına rağmen, ürünün soğuyup kalıptan dışarı atılabileceği sıcaklığa düşmesi uzun zaman almaktadır. Bunun tersi olarak, soğuk kalıpta ergimiş plastiğin soğuması çabuk olur ve kalıbı doldurmadan soğuyup sertleşir. Ergimiş plastiğin kalıp içerisindeki akışına yönelik olarak yapılan çalışmalar bu iki durumun, en uygun baskı süresini elde etmede alt ve üst sinırları belirlemeye yardımcı olduğunu göstermektedir (Uluer ve ark., 2005).

Kalıp 1sisinı belirlenen sicaklikta tutmak, genellikle kalıp içinde açılmış kanallarda su (veya başka sıvılar) dolaştırmakla sağlanır. Eriyik plastiğin 1sıs1, soğutma süresince değişir. Soğutma sisteminin tasarımı, enjekte edilen plastik parçanın geometrik yapısına bağlıdır. Plastiklerin kalıplanmasında enjekte edilen eriyik çok sıcak olduğundan, hızlı ve düzgün çekme sağlanmalıdır. Soğutma kanallarının konumu, 1sıyı en iyi taşıyabilecek konumda tasarlanmalidir (Tang ve ark, 1997).

Prasad ve ark. (1999), yaptıkları çalışmada, plastik enjeksiyon ile kalıplamada enjeksiyon süresine etki eden kalıp sıcaklığı, plastiğin erime sıcaklığı, plastiğin ağırlığı ve enjeksiyon basıncı gibi parametreleri MATLAB programında Levenberg Marquard algoritmasını kullanarak eğitmişlerdir. Eğitilen enjeksiyon süresinin gerçek uygulamadaki enjeksiyon süresi ile karşılaştırılması için MELTFLOW simülasyon programı kullanmışlardır. Levenberg Marquard algoritmasi kullanılarak eğitilen enjeksiyon süresi ile gerçek uygulamadaki enjeksiyon süresi arasındaki farkı görebilmek için farklı plastik malzemelerin kalıp boşluğuna dolma sürelerini hesaplamışlardır. Ağın ürettiği enjeksiyon sürelerinin gerçek uygulamadaki enjeksyon sürelerine çok yakın sonuç verdiğini tespit etmişlerdir. Ergüney ve ark. (2005), akış uzunluğu ile kalıbın dolup dolmayacağı tahmin edildiğinden spiral kanallı bir kalıpta farklı enjeksiyon parametrelerinin (silindir sıcaklığı, enjeksiyon basıncı, enjeksiyon debisi ve kalıp sicaklı̆ı) etkilerini araştırmak için plastiklerin akış uzunluklarını incelemişlerdir. Enjeksiyon parametrelerinin değerleri arttıkça akış uzunluğunun arttığını, en uzun akışın sırasıyla polistren $(450 \mathrm{~mm})$, poliproplen $(428 \mathrm{~mm})$, yüksek yoğunluklu polietilen (341 mm) ve düşük yoğunluklu polietilen $(324 \mathrm{~mm})$ de meydana geldiğini belirtmişlerdir. Çakır ve ark. (2001), I20-3 polietilen plastik ürünlerdeki çekme miktarını, enjeksiyon parametrelerini ve kalıp özelliklerinin etkilerini deneysel olarak araştırmışlardır. Yaptıkları deneylerde enjeksiyon sıcaklığı, enjeksiyon basınc1, katkı maddesi miktarı ve kalıplama süresinin plastik ürünlerde meydana gelen çekme miktarı oranları üzerindeki etkilerini inceleyerek, enjeksiyon basinc1 ve kalıplama süresinin artması ile çekmenin azaldığını, katkı maddesi ve enjeksiyon sicaklığının artmasıyla çekmenin arttı̆̆ını tespit etmişlerdir. Oktem ve ark. (2007), plastik ürünlerin üretimi esnasında, çekme pay1 değişimine bağlı olarak, hata problemlerini azaltmak için optimizasyon tekniklerini içeren bir çalışma yapmışlardır. Moldflow analizi ile L27 ve L9 Taguchi ortogonal tasarımın temel dağılımlarından yararlanarak çarpılmaya ve çekmeye etki eden parametrelerin değişimlerini analiz etmişlerdir. Analizler sonucunda, ütüleme 
basıncının \%58.03, ütüleme süresinin $\% 23.03$, enjeksiyon süresinin $\% 15.17$ ve soğutma süresinin \%3.68 oranında çarpılmaya yol açtığını; ütüleme süresinin \%84.054, ütüleme basıncının \%7.83, enjeksiyon süresinin $\% 5.528$ ve soğutma süresinin $\% 2.588$ oranında da çekmeye yol açtığını tespit etmişlerdir.

Sadeghi (2000), plastik enjeksiyon kalıpları için yapay sinir ağlarıyla ilgili bir çalışma yapmıştır. Ağ'a değişik plastik ürün malzemesi, enjeksiyon süresi, kalıp sicaklığı ve erime sicaklığ1 gibi değişkenler girilirken, bu değişkenlere bağlı olarak kalıp kalitesi, eriyik malzeme dolma süresi ve enjeksiyon basinc1 gibi parametrelerin nasil değiştiğini CAE yazılımını kullanarak hesaplamıştır. Ferreira ve ark. (2003), plastik enjeksiyon kalıpları için farklı soğutma sistemlerini geliştirmek ve kalıptaki problemleri azaltmak için algoritmik matris yöntemi geliştirmişlerdir. $\mathrm{Bu}$ yöntem ile plastik enjeksiyon kalıplarında oluşacak problemlerin önceden belirlenebildiğini ve gerekli değişiklikler yapılarak hatası üretimin yapılabileceğini belirtmişlerdir. Shelesh-Nezhad ve ark. (1997), enjeksiyon kalıplarındaki kalıp parametrelerinin (Erime sıcaklığı, kalıp sıcaklığı, enjeksiyon süresi ve enjeksiyon basincı) etkilerini tespit etmede akıllı sitemleri uygulamışlardır. Durum tabanlı çıkarsama (CBR) tekniğini ve hibrid uzman sistemi kullanarak optimum sınırlar içerisinde ergimiş plastiğin kalıp boşluğuna dolma uzunluğu ve bu uzunluktaki kalınlık değişimini incelemişlerdir. Buna bağlı olarak plastik enjeksiyon ile kalıplamada kalıp parametrelerine etki eden faktörler arasındaki ilişkiyi hesaplamışlardır.

\section{MATERYAL VE METOT}

Günümüzde kullanılan plastik parçaların üretimde kullanılan yöntemlerin başında plastik enjeksiyon yöntemi gelmektedir. Plastik enjeksiyon yöntemi ile hammaddesi Polipropilen(pp) olan granül halindeki plastik hammaddelerini 1s1 yardımıyla ergiyik haline getirilerek, istenilen şekilde parçaların kalıplanması ve istenilen şekilde şekillendirilmesi işlemleridir.

Plastik enjeksiyon yöntemiyle, karışık yüksek hacimli parçaların hızlı bir yöntem ve seri bir üretim ile imal edilmesi, maliyet konusunda düşük, otomasyonlara uygun, istenilen renk seçeneği, imalat sırasında malzeme kaybı çok az olması, aynı makinelerde farklı kalıplar bağlanarak farklı ürünler alınabilmesi özellikleri konusunda oldukça avantajlı bir yöntemdir. Elektirkli (Zhafir VE4500 450 ton) ve hidrolik (Haitian Ma4800 480 ton) olmak üzere plastik enjeksiyon makinaları üzerinde yaptığımız bu çalışmada; üretim esnasında ve öncesinde tespit ettiğimiz problemleri ve çözüm yolları aşağıda sıralanmıştır.

\section{Plastik Enjeksiyon Makinalarında Kontrol Ünitelerinin Çalıșma Şartlarının Belirlenmesi}

\section{Sıvı malzemenin ısı kontrolü ve kalıp içerisine malzemenin alım miktarının ayarlanması}

Plastik enjeksiyon prosesine başlamadan önce hammadde firmasından alınan değerler ile sıcaklıkları ayarlamamız gerekmektedir. Alınan hammadde özelliklerini firmanın verileri incelenerek, enjeksiyon prosesi sırasındaki ocak 1sıları istenilen dereceye getirilmektedir.

Enjeksiyon makinelerinin ocak büyüklüklerine göre gerekli adetlerde seramik rezistanslar ile malzeme eriyik hale getirilir. Her bir 1sitıcinın olduğu bölgeye isim verilmektedir. Şekil 1.a'da görüldüğü üzere 5 bölgeden oluşmaktadır. Bölge 1sitıcilarında istenilen değeri set bölümüne yazilmaktadir. Max (-) ve $\max (+)$ ise verilen tolerans değerleridir. Gerçek satırında ise termokopulun ölçtüğü anlık değer gösterilmektedir. Bölge adları kalıba yakın olan tarafa bölge -1 adı verilerek enjeksiyon ünitesine doğru siralama ile giderek adlar verilmektedir. Yük huni denilen bölgede ise set istenilen değer girilir. Hammadde huniden ocağa doğru hareket edeceği için orada 1sıdan dolayı erimemesi için sürekli su ile soğutma kanalları ile soğutma işlemi sağlanmaktadır. Eğer burada eriyik malzeme oluşur ise malzemenin vidaya akışı sağlanmaz.

Enjeksiyon prosesinde malzeme alma sayfasında, ürün miktarı hesap edilen değerlerde girilerek prosese başlanır. Araştırmada hidrolik ve elektrikli makinler ile çalışmalar yaptık. Her makinenin ocak çap1 ve mil boyutu farklı olduğundan dolayı mal alma sayısı değişiklik göstermektedir. Aynı ürünü farklı makinelerde çalıştığımızda; 450 tonluk elektrikli makinede ürün mal alma sayıs1 199,4 iken 480 tonluk hidrolik makinede ise 153,2 ile çalışmaktayız. Eğer malzeme alma sayımı 153,2 olması gerekirken yüksek ise ürün çapaklı gelebilir ve dişi kalıpta kalması sık karşılaşılan bir sorun ortaya çıkmaktadır, mal alma 
sayımız 153,2 olması gerekirken sayımız düşük ise oluşan üründe eksikler mevcut olmaktadır.

Malzeme alma sayısı ayarlanırken, malzeme alma hızı ve basıncida ayarlanmalıdır. Malzeme alma sayısı büyük ise daha düşük hız ve basınç ile ayarlanır. Üretilen malzemenin içine boya, kalsit vb. malzemeler katıliyorsa malzeme alma sayfasından geri basınç verilerek eritilmekte olan kovanın içinde malzeme karışımı istenilen oranda olmasını sağlamaktadır.

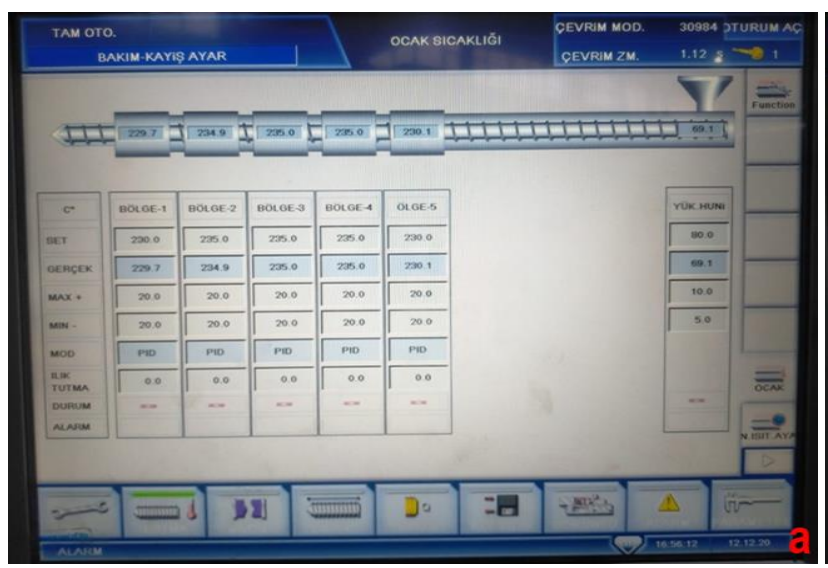

Şekil 1. Plastik enjeksiyon makinesi a) Ocak 1sı kontrol sayfası b) Malzeme alma kontrol sayfası

\section{Kalıp açılma ve kapanma oran ve sürelerinin ayarlanması}

Mengeneye bağlanan kalıp açılış pozisyonu gerektiği kadar açılmalıdır. Fazla açılma çevrim süresinin artmasına neden olmaktadır. Bu nedenle minimum açılacak şekilde ayarlanmalıdır. Kapanış ve açılış hız ve basınçları ayarlamak önemlidir. İlk açılış hızı çok hızlı olmamalıdır. Yavaş açılarak yavaş kapanması istenir. Kapanırken ise basınç yüksek ve hız düşük olmalıdır. Eğer bu sistemde çalışılmaz kalıp hızlı açılır ise ürünün dişide kaldığı görülmüştür. Hızlı kapanması durumunda ise dişi ve erkek kalıp yüzeylerinde çarpışmalar tespit edilmiştir. Kalıbın zarar görmemesi ve ürünün dişide kalmaması için kapatma ve açılma hızları ve basınçları kademeli olarak ayarlanmalıdır.

Klp. Aç. Strok (kalıp açma değer alanına gelen) değeri dişi ve erkek kalıp arasında birbiri ile temas eden yüzeylerin arasındaki mesafenin kaç $\mathrm{mm}$ açılacağı değer girilir. Mengene sayfası iki aşamada yapılır. Üst satırda gösterilen mengene kapatma
Malzeme alma sayfasında istenilen ürünün oluşması için gerekli mal değeri girilmektedir. Bölge kısmına yeterli adet girilir. Şekil 1 b'de görüldüğü üzere 3 girilmiştir. Bölgeler ise S1, S2 ve son değer SE olur. Küçük ürünlerde eşit şekilde mal alım sağlanırken büyük ürünlerde ise ocak 1sıları yetişemediğinden ötürü mal alma daha yavaş yapılmaktadır. Malzeme alma yapilırken her bölgeye hız ve basınç verilmektedir. Geri basınç ise daha basınçlı ve daha iyi karışmasını sağlayarak ürünün homojen olmasına sebep olmaktadır.

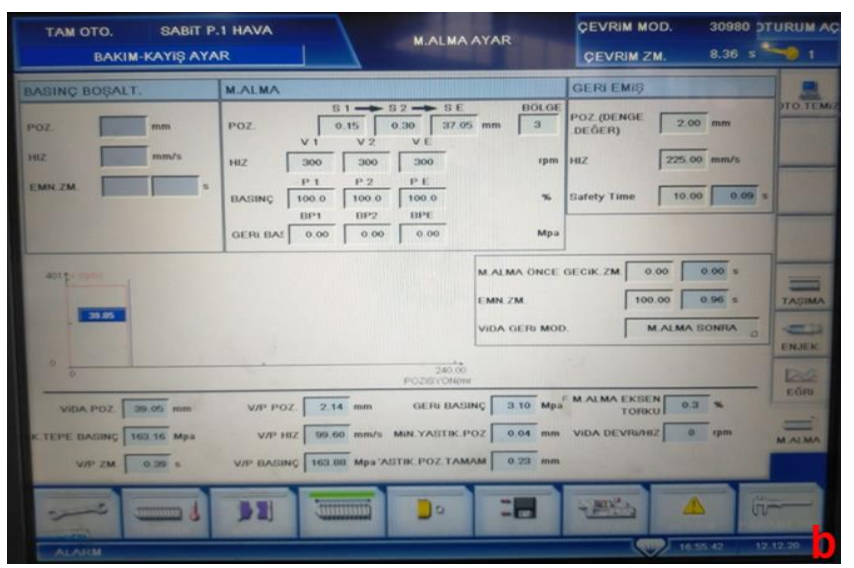

sayfası değerleri girilmektedir. Yüksek hız ve basınç ile harekete başlayan mengene kapanmaya yakın düşük basınç ve hız ile yavaşlar ve daha sonra yüksek basınç ve düşük hız ile kendini kitler. Elektrik ve hidrolik makinelerde işlem aynıdır. Mengene açma sayfasında ise bu işlem iki farklı şekilde oluşmaktadır. Şekil 2.a de hidrolik bir makine örnek verilmiştir. Mengene kapatma işlemi soldan sağa doğru olurken mengene açma işleme ise sağdan sola doğru olmaktadır. Mengene ilk 6-7 mm pozisyonda olarak yavaş hız ve basınç ile açılır, daha sonra kademeli olarak pozisyonlar verilir. $\mathrm{Bu}$ pozisyonlar mengene açılma pozisyonu $450 \mathrm{~mm}$ olur ve daha sonra son pozisyonlara doğru hiz ve basınçlar yavaşlatılır. Mengene sona doğru frenlemede vuruntu olmaması için. Sonra hızlar ve basınçlar artarak devam eder. İstenilen açılma pozisyonuna gelirken hızlar ve basınçlar tekrardan yavaşlatılır. Sebebi ise kendini frenlememesidir. Ama elektrikli makinelerde ise servo motorlar ile mengene açılımı sağlandığ için mengene açılımında ilk hız yavaş olur daha sonra istenilen pozisyona 
kadar son hız ile açılır ve her daim sabit değerde aç1lır.

\section{Kalıp tonajunın belirlenmesi}

Mengeneye bağlanan kalıp çalışmadan önce kalıp ayarı yapılması gerekmektedir. Kalıp ayarı minimum tonaj ile yapılarak kalıba zarar azaltılır. Tonaj hesabı ile yaklaşık tonaj girilir. Eğer ürün çapağa kaçıyor ise kalıp tonajı düşük olabilir. Eğer üründe gaz var ise gaz kanalları gazı atamaz ve gazlı ürün gelebilir. Bazı makinelerde tonaj sayfası olup tonaj değeri girilirken, bazı makinelerde ise kalıp kapama sayfasında en son değerdeki basınç değerine girilen değer olarak almaktadır.

Şekil 2.b'de verilen kalıp kalınlığı ise kalıbın iki mengene arasında uzunluk değerine $5-10 \mathrm{~mm}$ daha fazla girilerek kalıp ayarı yapılmaktadır. Bu işlemlerin hepsi güvenlik tedbiridir.

\section{Plastik enjeksiyon hızları ve basınçları kontrolü}

Plastik enjeksiyon prosesinde eriyik malzeme kalıp içine doldurulurken enjeksiyon hızları ve basınçları önemli etkendir. Küçük parçalar üretilirken genelde yüksek hız ve basınç ile enjeksiyon yapılır. Büyük ve kalın parçalarda ise hızlar ve basınçlar düşük şekilde enjeksiyon yapılmaktadır. Enjeksiyon hız ve basınçlarının yanı sıra ütüleme işlemi bu aşamada yapılmaktadır. Ütüleme basınç ve hız verilerek belli aralıklarla yapılmaktadır. Kalın ve büyük parçalarda ütüleme çok önemli bir etkendir.

Şekil 3.a'da ilk satır eriyik malzemeyi kalıp içerisine kovanda bulunan eriyik malzeme millin hareketi ile kalıba hareket eder. Bu işlem yapılırken belli pozisyon aralıklarında belli basınç ve hızlar ile kalıba enjeksiyon yapılır. Kalıp içerisinde ilk madde geçişi kalın cidar ise malzemenin ilk bölümü dolana kadar hızlar ve basınçlar yavaş daha sonraki pozisyonda ise hız basınç yüksek verilir.

\section{Ürünün kalıptan çıkışını sağlayan hava kontrol sistemi}

Plastik enjeksiyon prosesi sırasında oluşan malzeme (ürün) kalıptan çıkarılması için itici ve hava pimleri kullanılmaktadır. Kalıbın dişide kalmaması için dişi hava pimi mevcuttur. Erkek kalıpta ürün ise hava, sıyırıcı, maça ve hava pimleri ile düşürülmektedir. Üretim bandında bulunan ürünlerin kalıptan çıkarılmasında büyük kolaylık sağlar.
Şekil 3.b'de görülen her airblow havayı ifade eder. Kalıpta oluşan ürününün düşürülmesi için belli havalar vuruşları gereklidir. Sisteme ve kalıba uygun hava vuruş metodu seçilerek, belli pozisyonlarda belli saniyeler bekleyerek istenilen sürelerde hava vuruşu sağlanmalıdır.

\section{Çevrim sisteminin kontrolü}

Plastik enjeksiyon prosesi sırasinda tüm hareketlerin hesab1 yapılarak çevrim hesabı çıkarılmaktadır. Şekil 4'te bir parçanın üretimim sırasında hangi hareketinde kaç saniyede işlem yaptığını belirtir. Isşlem basamağının sonunda ise toplam net çevrimi verir.

\section{Soğutma sistemleri}

Plastik enjeksiyon imalatı yapan işletmeler genellikle iki farklı soğutma sistemi kullanmaktadırlar. Bu sistemler su soğutma kulesi ve chiller'dir. Kalıp içerisindeki eriyik malzemenin katılaşması için düşük derecede su soğutma sistemi chiller ile yapılırken, plastik enjeksiyon makilerin yağ soğutmaları için su soğutma kuleleri tercih edilmektedir. Şekil 5.a'da soğutma kulesine ait soğutma suyunun eksen başlıklarındaki sıcaklık değerleri verilmiştir.

Soğutma kuleleri, farklı amaç için işleyen endüstriyel tesislere, cihazları veya ürünü soğutmak için soğutma suyunu sağlayan yapılardır. Sistemde dolaşan soğutma sıvısının sistemden veya üründen aldığ 1sıyı uzaklaştırmak için tercih edilir. İki ana başlıkta sınıflandırılır. Bunlardan ilki 1slak soğutma kulesi diğeri ise kuru soğutma kulesidir.

Islak soğutma kulesi buharlaşma mantı̆g ile çalışır. Kuru soğutma kulesi ise çevreyle etkileşime geçerek sıvının soğumasını hava yardımıyla yapmaktadır.

Kompresör, genleşme vanası, evaporatörden ve kondanser oluşan chiller soğutma sistemleri, kompresörde sıkıştırılan ve isınan gazın kondanserde soğutulması ile çalışır. Ardından genleşme vanasından geçen gazın basıncı sayesinde 1S1 transferi gerçekleşir ve sicaklık düşer. Evaporatörden geçerken soğutulması amaçlanan sıvıdaki 1sıyı alır alçak basınçla kompresöre gaz halinde ulaşır ve yeniden sıkıştırılır. Chiller soğutma sistemine ait eksen başlıklarındaki su giriş çıkış sıcaklıkları Şekil 5.b'de verilmiştir. 

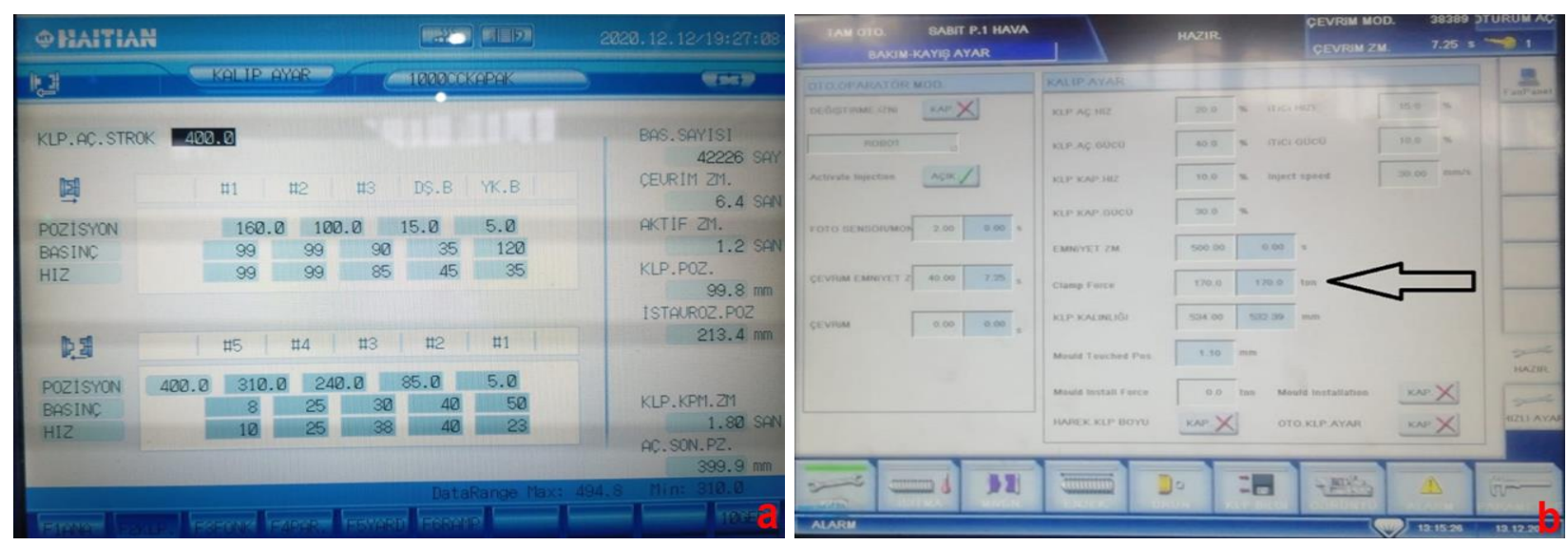

Şekil 2. Plastik enjeksiyon makinesi a) Mengene kontrol sayfası b) Kalıp tonaj kontrol sayfası
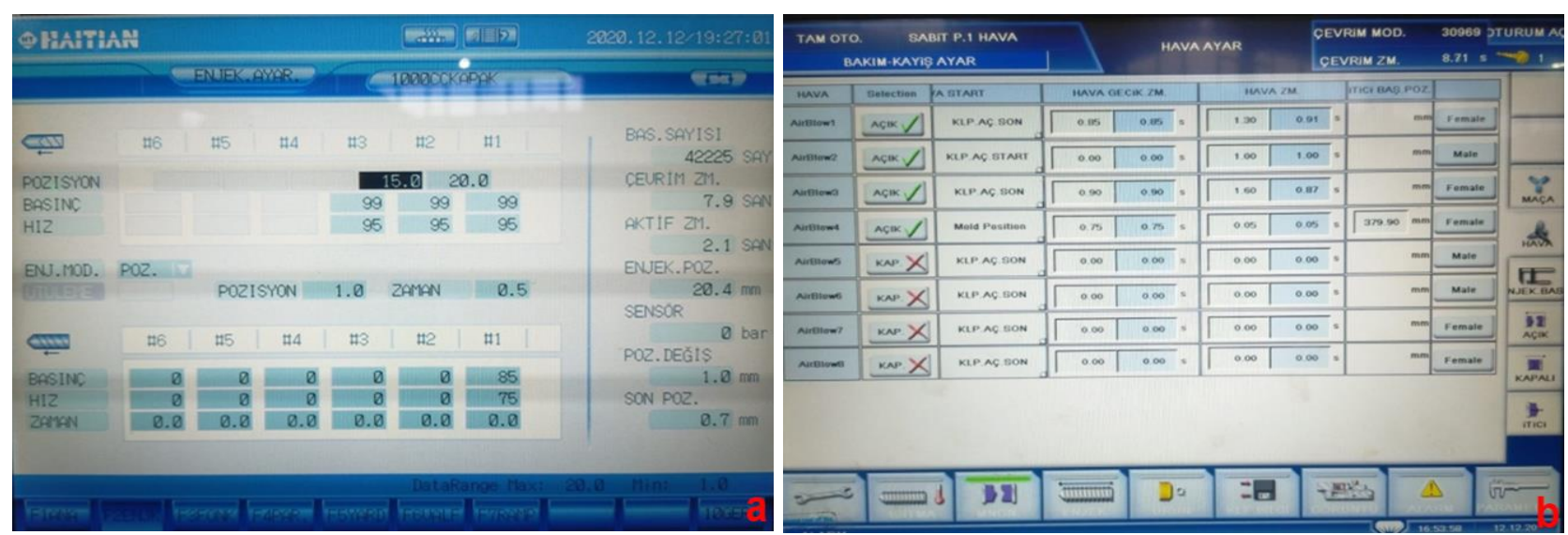

Şekil 3. Plastik enjeksiyon a) Hız ve basınç kontrol sayfası b) Hava kontrol sayfası

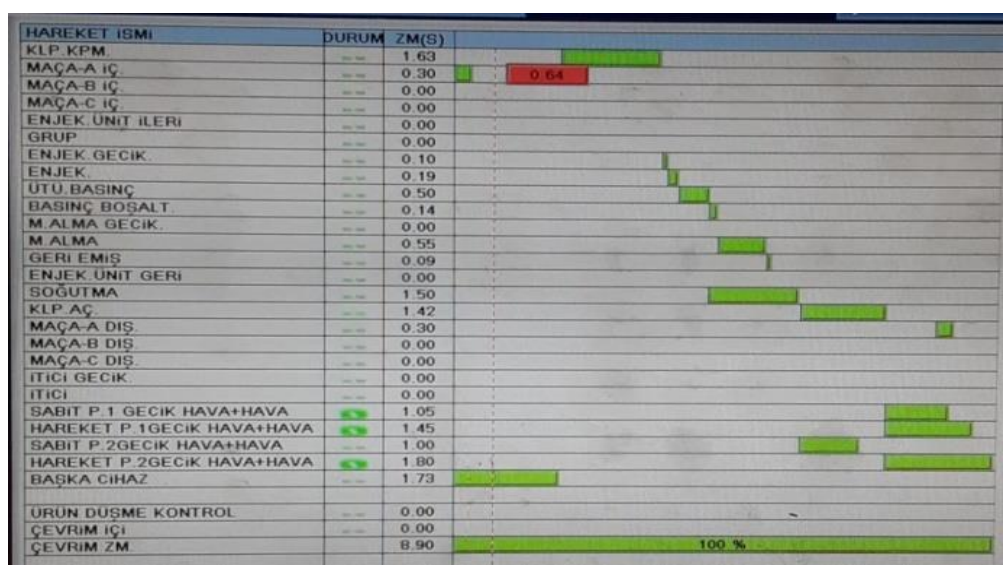

Şekil 4. Plastik enjeksiyon makinesi çevrim kontrol sayfası 

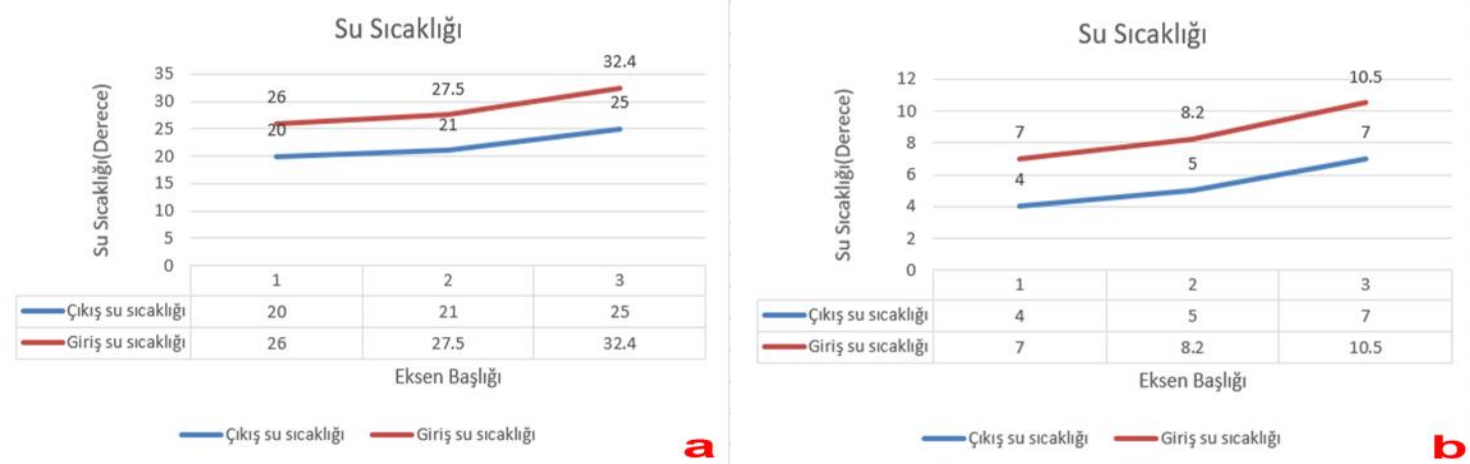

Şekil 5. a) Soğutma kulesi su giriş-çıkış sıcaklık grafiği b) Chiller soğutma sistemi su giriş-çıkış sıcaklık grafiği

\section{BULGULAR VE TARTIŞMA}

\section{Plastik Enjeksiyon Prosesinde Tespit Edilen İmalat Hataları ve Çözüm yolları}

Endüstride bir çok sistemin imalatında ve işletilmesinde hatalar olduğu gibi enjeksiyon sisteminde de imalat hataları bulunmaktadır (Kahraman ve Taşgın, 2019). Enjeksiyon sistemi kullanılarak oluşturulan parça imalatında oluşan hatalar işlem öncesi hammadde depolanmasının yanlış olmasından, işlem süresi boyunca oluşan hatalardan ve paketlenmeden kaynaklı olduğu tespit edilmiștir.

Üretim işlemi sırasında oluşan hatalar öncesi veya sonrasında oluşan hatalara göre daha karmaşı ve zor çözümlere sahip olabilir. İşlem sırasında muhtemel karşılaşılabilir hatalar; makine, kalıp, çalışma ortamının şartları, hammadde ve parça tasarımdan kaynaklı olduğu.

Enjeksiyon sisteminin düzgün ve optimum çalışması 3 ana şarta bağlıdır. Bunlar; basınç, sıcaklik ve zaman sabitleridir. Oluşan problemlerin birçoğunun ise bu sabitlerin kaymasından veya hatalı işlemlerden kaynaklandığı gözlenmiştir.

\section{Malzemede yanık olușumu}

Kalıp içindeki boşluğu dolduran erimiş haldeki plastik malzeme yüzünden sıkışan hava kalıptan dışarı doğru tahliye edilmelidir. Eğer tahliye işlemi gerçekleşmez ise ve kalıp içinde hava kalırsa, kalıp içinin ulaştığı yüksek sıcaklıkları nedeniyle plastik malzeme ile arasında kimyasal reaksiyon oluşarak gazın yanmasına, bunun sonucunda da Şekil 6.a'da görüldüğü gibi yanık izine neden olduğu gözlenmiştir. Eğer gaz yanarsa yani dizel etkisi oluşursa oluşan parçada siyah veya hafif sarı izler oluşabilir. Normal şartlarda kalıp içinde sıkışan hava itici pimler yardımıyla tahliye edilebilir. Yanık oluşmaması için sistemin elemanları düzenli periyotlar ile kontrol edilmelidir. Ayrıca yanık izini önlemek adına erimiş plastik malzeme sıcaklığı azaltılabilir ve parçanın keskin köşeleri yuvarlatılabilir. İşlemde oluşacak değişiklikler ürünün temiz ve kaliteli oluşmasına yardımcı olacaktır.

\section{Akış izi hataları}

Kalıp içindeki boşluğa doğru akan erimiş malzeme gittiği yolun kesit alanına göre hızında değişiklik yaşanır. Erimiş malzemenin yoluna parçanın şeklini değiştirecek farklı bir cisim çıktığında türbülans oluşur. Bu nedenle akış bölünür. Bir veya birden çok türbülans oluşturması oluşan parça üzerinde Şekil 6.b'de görüldüğü gibi akış izlerine neden olduğu gözlenmiştir. Erimiş malzeme sicaklığı arttırmak veya enjeksiyon hızını yükseltmek akış izlerinin oluşmamasını sağlayabilir. Konik besleme yerine yolluk girişini yandan yapmak ya da tünel girişini kullanmak oluşacak akış izlerini azaltmanın farklı bir yoludur.

\section{Birleşme noktalarındaki hatalar}

Akış yollarının çakıştığ bölgelerde birleşme izleri gözlemlenmiş olup. Kalıpta eğer birden çok yolluk girişi bulunuyorsa, erimiş malzeme yollukların birleşmesi boyunca donduğu nokta varsa, Şekil 6.c'de görüldüğü gibi parçanın yüzeyinde uzun birleşme izleri tespit edilmiştir. Birleşme izleri görüntü bozukluğunun yanı sıra parçanın mekanik olarak bozulmasını sağlar. Parçanın mukavemetini azaltır.

Soğuk birleşme nedeniyle oluşan izleri azaltmak için enjeksiyon ve kalıp içi sıcaklığını 
arttırma ve enjeksiyon hızını arttırmak gereklidir. Enjeksiyon hızını belirli oranda artırılmalıdır,

\section{Eksik üründen kaynaklı hatalar}

Kalıp içine tam olarak dolması gereken malzemenin eksik kalması nedeniyle Şekil 6.d'de görüldüğü üzere üründe hatalar oluşmuştur. Kalıp içinde sıkışan hava basınç oluşturur. $\mathrm{Bu}$ oluşan basınç enjeksiyon sisteminde oluşan basınçtan büyük olursa erimiş haldeki plastik malzeme kalıp içine dolamaz ve oluşan üründe eksiklikler meydana geldiği gözlemlenmiştir. Özellikle ince kesitli veya uzun boylu parçalarda gözlemlenen bir hatadır. Enjeksiyon basıncının artırılması çözüm olabilir ama yolluk girişi bölgesinde durmadan gerilme yaşatacağ 1 için farklı hatalarla karşılaşma ihtimali yüksektir. Eksik ürün hatasından kurtulmak için enjeksiyon hızının artırılması en doğru yöntemdir. Kalıp sicaklığının artırılması kullanılan yöntemlerden birisidir fakat maliyet artışı sağlar.

\section{Parçanın dişi kalıptan ayrılmamasından kaynaklı hatalar}

Üretilen parçanın, erkek ve dişi kalıp birbirinden ayrıldıktan sonra dişi kalıptan ayrılması gerekmektedir. Eğer kalıp ürün çıkış açıları yetersizse veya çıkıntı kenarlarında parlatma eksik yapılmış ise ürünün kalıptan ayrılmasında Şekil 6.e'de görülen sorunlar gözlemlenmiştir. Parçaların iyi parlatılması ve açıların uygun oluşturması hatanın önüne geçmiştir.

\section{Çapaklı ürün oluşum hataları}

Kalıp nedeniyle üründe çapak oluşur (Şekil 6.f). Kalıp birleşmesi uygun olmalı ve aşınma olmamalıdır. Enjeksiyon sisteminde oluşan yüksek basınç sistemin kalıp kapanma kuvvetinden büyük olmamalıdır. Eğer bu şartlara sağlanmazsa oluşan üründe çapaklar gözlenmiştir. İş gücü artırılması ile çapaklar elle temizlenebilir fakat bu maliyet ve zaman açısından zarar uğratmaktadır.

\section{Yüzeyde çöküntü oluşması hataları}

Üretilen parça, tam anlamiyla soğutulmadan kalıptan erken ayrıldığında Şekil 6.g'de görüldüğü gibi çöküntüler gözlemlenmiştir. Soğuması zor olduğu için daha çok kalın etli parçalarda gözlemlenir. Oluşan çökme hatası enjeksiyon veya malzemeden kaynaklı değildir. Tutma basıncının yetersizliği ve süresinin az olmasından dolayı çökmelerde basınç ve süre artırılırsa çökmelerin önüne geçilebilir fakat bu durumun parçada kalıp içi basıncın artmasına neden olduğu gözlemlenmiştir.

\section{Çarpılma hataları}

Kalıbın yeterince soğumaması halinde üretilen malzeme kalıptan çıkartılırken çarpılmaya uğrayabilir. Yetersiz ve az süreli soğutma üretilen parçada çarpılma neden olmuştur. Üretilen plastik parçanın hammaddesinin çarpılma değerlerine göre soğutma derecesi ayarlanmalıdır.

Ürünü tasarlarken farklı derinlik ve et kalınlıkları olursa, ince taraf kalın tarafa nazaran daha çabuk soğumaya başlar. $\mathrm{Bu}$ nedenle parça içinde iç gerilmelere neden olmaktadır. İç gerilmeler Şekil 6.h'de görüldüğü gibi çarpılmaya yol açmıştır. Çarpılma olmaması için ince bölümler desteklenir. Ayrıca yüksek enjeksiyon basıncinın engellenmesi ve kalıp içi sıcaklığın artırılması çarpılmayı azaltmıştır.

\section{Hızlı akış izi hataları}

Enjeksiyondan çıkan erimiş plastik malzemenin akış hızının, olması gerekenden fazla olması durumunda kalıp içine yolluk girişinden fişkırdığ görülmüştür. Malzeme kalıp içinde düzensiz bir şekilde yayılır. Kendisinden sonra kalıbın içine gelen plastik erimiş malzeme ile heterojen bir yap1 oluşturur. $\mathrm{Bu}$ hatanın oluşmaması için yolluk giriş konumlarının uygun tasarıma sahip olması gereklidir. Fan yolluk girişi kullanılması çözüm olacaktır.

\section{Hava boșluğu olușum hataları}

Viskozitesi fazla olan erimiş plastik malzemenin kullanıldığı parçalarda kalıp içindeki boşluğa sıkışan gaz hacim kaplar ve boşluk oluşturur (Şekil 6.I). Kesit alanı kalın olan yerdeki çekme hareketi, tutma basincından büyük olduğu için oluşan parçada hava boşlukları oluşmuştur. Boşluk oluşmasını engellemek için tutma basıncını artırabiliriz veya proses süresi uzun tutulmalıdır. 


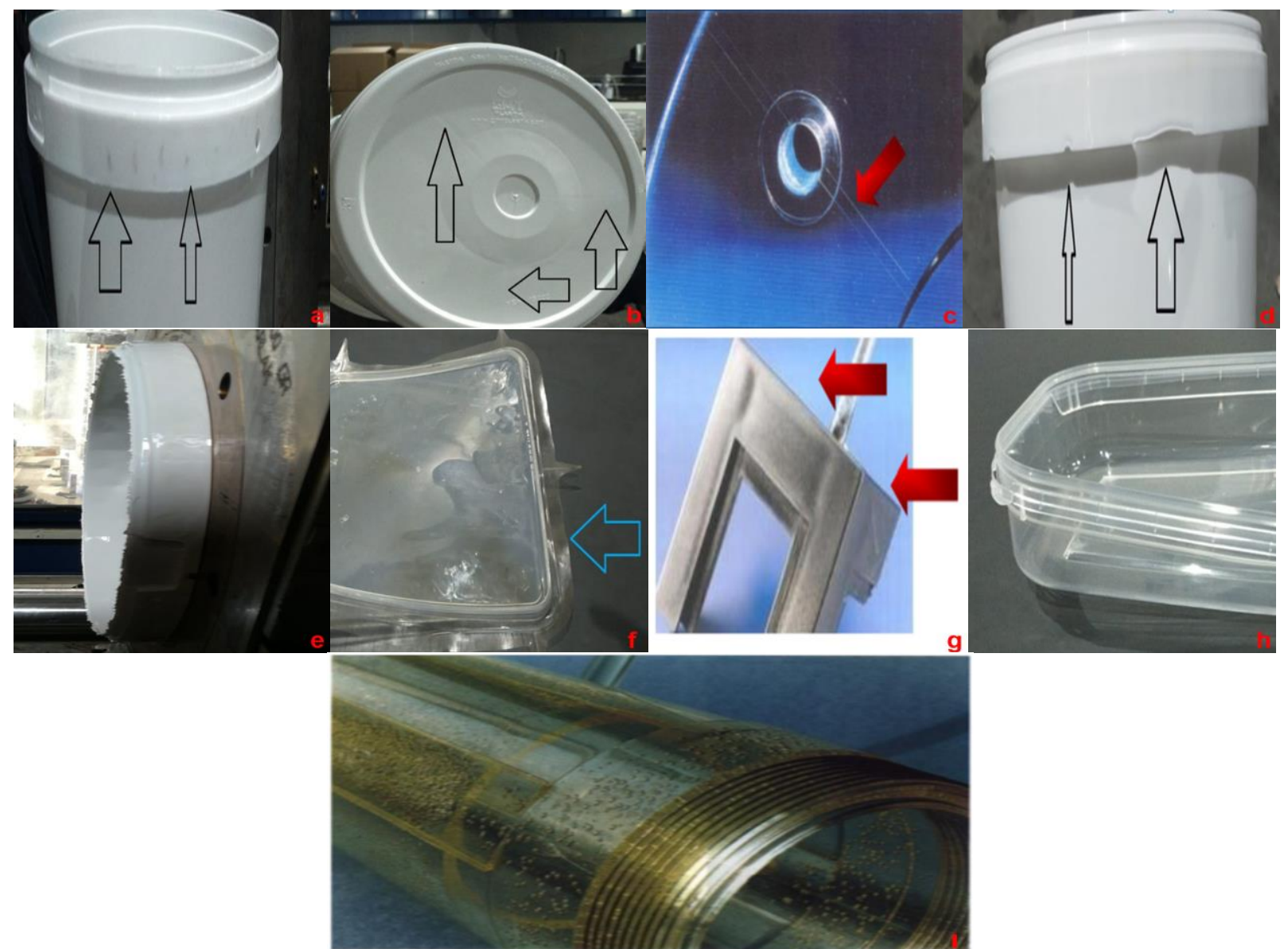

Şekil 6. a)Yanık izi oluşan parça b) Akış izi oluşan parça c) Soğuk birleşme izleri d) Eksik ürün e) Dişi kalıpta kalan ürün f) Çapaklı ürün g) Parça yüzeyindeki çöküntü h) Çarpılmış ürün I) Vakum boşluklu parça

\section{SONUC}

Yaptığımız çalışmalar sonucu plastik parça imalatında karşılaşılan sorunlar ve hatalar genellikle hammadde, parça tasarımı, makine ayarları, kalıp imalatı ve çalışma prosesi sonucunda meydana çıktığı gözlemlenmiştir. Bazı hataları fark etmek çözümleri hemen ulaşılabilmesinin aksine bazı hataların hangi nedenle meydana geldiğinin tespiti zaman alabilmektedir. En önemli unsur plastik enjeksiyon prosesi sırasında hatanın doğru tespit edilmesidir. Doğru tespit edilen hatalarda zamandan ve işçilikten kazanç elde edilmektedir. İmalat sırasında hangi hataların hangi parametreler ile çözülebileceği tespit edilerek belirlenmelidir. Eğer oluşan hatalar kalıptan kaynaklı ise, bu sorunların çözülmesi için zaman maliyeti verecektir. Kalıp tekrardan onarilarak yeni hal alarak deneme sürecinde geçirilecektir. Bu nedenle parça tasarımı önemli etkendir. Parça tasarımı sırasında plastik enjeksiyon analizi programı kullanarak oluşacak hatalar azaltılabilmektedir.

Plastik enjeksiyon prosesi parça tasarımı ile başlar. Tasarlanan parçaya kalıp tasarım yapılarak kalıp üretilir. Üretilen kalıp enjeksiyon makinesine bağlanır. Kalıp bağlandıktan sonra ise enjeksiyon makinesi kontrol ekranında makine ayarları yapılmaktadır. Enjeksiyon ayarlarından sonra proses devam ederek eriyik malzemeye meme yoluyla kalıba yön alarak istenilen parça elde edilmektedir. Plastik enjeksiyon prosesi ile seri ve hızlı üretim mümkündür. Genellikle enjeksiyon makineleri robotlar ile ortak çalışma sağlayarak güvenilir bir ürün elde ederek kalıp ve makinenin güvenliğini sağlamaktadır.

Malzemede yanık oluşumu, kalıp içerisinde hava kalarak yüksek basıç etkisitle reaksiyona girmesinden kaynaklı olup, itici pimlerle havay1 çıkartmak gerekir. 
Akış izi ve birleşme noktalarındaki hataları enjeksiyon hızını yükselterek gidere biliriz.

> Parça kalıpta kalıyorsa kalıbın çıkış açıları yada yüzey parlaklığg yeterli değil demektir.

> Kalıpların birleşme yerlerinde aşınma olması yada ürünün tam katılaşmadan kalıptan çıkarılması ürünün çapaklı, çarpılmış ve yüzeyinde çöküntülü çıkmasına neden olmaktadir.

Üretim esnasında oluşan sorunların geç fark etme durumunda ise büyük masraf ve zararlar mevcut olmaktadırlar. Proses ilk başladığı zaman hata olmayan makineler belli süre çalıștıktan sonra hatalar meydana gelebildiği görülmüștür. $\mathrm{Bu}$ nedenle proses işlemine başlamadan önce ayarlar yapılırken karşılaşabileceğimiz hataları önlemek için dikkatli olunması ve prosesin takip edilmesi gerekmektedir.

Plastik enjeksiyon prosesi sirasinda en verimli sonuç ile parça üretiminde en iyi kalitenin yakalanması için günümüzde mevcut olan plastik enjeksiyon analizi programlarının parça tasarımıyla başlayıp istenilen ürünün imalatına kadar geçen zamanda mantıklı bir şekilde kullanılarak güvenilir ve istenilen özellikte üretim sağlana bileceği görülmüştür.

\section{ÇIKAR ÇATIŞMASI BEYANI}

Yazarlar bu makale ile ilgili herhangi bir çıkar çatışması bildirmemektedir.

\section{ARAŞTIRMA VE YAYIN ETİĞİ BEYANI}

Yazarlar bu çalışmanın araştırma ve yayın etiğine uygun olduğunu beyan eder.

\section{KAYNAKLAR}

Aisa, J. C., Javierre, J.A., Serna, D. (2006). An example of simulation tools use for large injection moulds design: The CONTENURTM 24001 solid waste container. Journal of Materials Processing Technology, 1759, 15-19. https://doi.org/10.1016/j.jmatprotec.2005.04.006

Çakır, Y., Özdemir, A. ve Güldaş, A. (2001). Plastik ürünlerde çekme miktarına etki eden enjeksiyon parametrelerinin incelenmesi, Teknoloji Dergisi, Sayı 1-2, 19-29.

Ergüney, S., Karataş, Ç. ve Sarıtaş, S. (2005). Ticari plastiklerin kalıpta akış boylarının incelenmesi, Gazi
Üniversitesi Mühendislik Mimarlık Dergisi, Cilt 20, No 3, 297-303.

Ferreira, J.C, Mateus, A. (2003). Studies of rapid soft tooling with conformal cooling channels for plastic injection moulding. Journal of Material Processing Technology, 142, 508-516. https://doi.org/10.1016/S0924-0136(03)00650-2

Fu, M.W., Fuh, J.Y.H., Nee, A.Y.C. (1999). Undercut feature recognition in an injection mould design system. Computer-Aided Design, 31, 777-790. https://doi.org/10.1016/S0010-4485(99)00070-6

Hui, K.C. (1997). Geometric aspects of the mouldability of parts. Computer-Aided Design, 29, 197-208. https://doi.org/10.1016/S0010-4485(96)00064-4

Kahraman, G., Taşgın, Y. (2019). Hidroelektirik santrallerde generatör stator sargı arızaları ve çözüm yöntemleri. DÜMF Mühendislik Dergisi. (10), 641-646. 10.24012/dumf.451184

Kitayama S, Miyakawa H, Takano M, Aiba S (2017) Multiobjective optimization of injection molding process parameters for short cycle time and warpage reduction using conformal cooling channel. Int $\mathbf{J}$ Adv Manuf Technol 88:1735-1744. https://doi.org/10.1007/s00170-016-8904-x

Kuo C, Dewantoro G, Huang C (2015) Optimization of injectionmolded light guide plate with microstructures by using reciprocal comparisons. J Intell Manuf 26:677-690. https://doi.org/ 10.1007/s10845-013-0826-y

Li J, Laghari RA (2018) A review on machining and optimization of particle-reinforced metal matrix composites. Int J Adv Manuf Technol. https://doi.org/10.1007/s00170-018-2837-5

Nardin, B., Kuzman, K., Kampus, Z. (2002). Injection moulding simulation results as an input to the injection moulding process. Journal of Materials Processing Technology, 130-131, 310-314. https://doi.org/10.1016/S0924-0136(02)00734-3

Oktem, H., Erzurumlu, T., Uzman, I. (2007). Application of Taguchi optimization technique in determining plastic injection molding process parameters for a thin-shell part. Materials and Design, 28, 12711278 .

https://doi.org/10.1016/j.matdes.2005.12.013

Prasad, K.D.V, Y., Eric.C.W, C. (1999). A neural network system for prediction of process parameters in pressure die casting. Journal of Material Processing Technology, 89-90 (1999) 583-590. https://doi.org/10.1016/S0924-0136(99)00071-0

Sadeghi, B.H.M. (2000). A BP- neural network predictor model for plastic injection molding process. Journal of Materials Processing Technology, 103, 411-416. https://doi.org/10.1016/S0924-0136(00)00498-2

Shelesh-Nezhad, K., Siores, E. (1997). An intelligent system for plastic injection molding process design. 
Journal of Materials Processing Technology, 63, $458-462$.

https://doi.org/10.1016/S0924-0136(96)02664-7

Tang, L.Q., Chassapis, C., Manoochehri, S. (1997). Optimal cooling system design for multicavity injection molding. Finite Element in Analysis and Design, 26, 229-251. https://doi.org/10.1016/S0168-874X(96)00083-2

Tian M, Gong X, Yin L, Li H, Ming W, Zhang Z, Chen J (2017) Multi-objective optimization of injection molding process parameters in two stages for multiple quality characteristics and energy efficiency using Taguchi method and NSGA-II. Int $\mathrm{J}$ Adv Manuf Technol 89:241-254. https://doi.org/ $10.1007 / \mathrm{s} 00170-016-9065-7$

Tsai K, Luo H (2017) An inverse model for injection molding of optical lens using artificial neural network coupled with genetic algorithm. J Intell Manuf 28:473-487. https://doi.org/ 10.1007/s10845014-0999-Z

Uluer, O., Güldaş, A., Özdemir, A. (2005). Ergimiş plastiğin kalıp boşluğundaki gerçek akış davranışının gözlenmesi için kalıp tasarımı ve imalatı. Teknoloji, 8, 181-189.

Zhao J, Cheng G, Ruan S, Li Z (2015) Multi-objective optimization design of injection molding process parameters based on the improved efficient global optimization algorithm and non-dominated sortingbased genetic algorithm. Int J Adv Manuf Technol 78:1813-1826. https://doi.org/10.1007/s00170-0146770-y 